\title{
Prognostic value of a-fetoprotein and des- $\gamma$-carboxy prothrombin responses in patients with hepatocellular carcinoma treated with transarterial chemoembolization
}

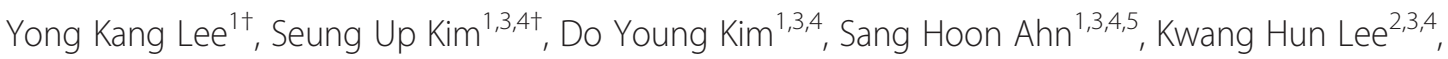

Do Yun Lee $e^{2,3,4}$, Kwang-Hyub Han ${ }^{1,3,4,5}$, Chae Yoon Chon ${ }^{1,3,4}$ and Jun Yong Park ${ }^{1,3,4^{*}}$

\begin{abstract}
Background/Aims: Alpha-fetoprotein (AFP) and des-gamma-carboxy prothrombin (DCP) have been used as diagnostic tools for hepatocellular carcinoma (HCC). However, prediction of outcome using AFP and DCP has not been elucidated. We investigated the clinical role of AFP and DCP as predictors of treatment outcome in patients with HCC undergoing trans-arterial chemoembolization (TACE).

Methods: Between January 2003 and December 2005, we enrolled 115 treatment-naïve patients who received TACE as an initial treatment modality. An AFP or DCP response was defined as a reduction of more than $50 \%$ from the baseline level 1 month after TACE. Patients with AFP $<20 \mathrm{ng} / \mathrm{mL}$ or DCP $<20 \mathrm{mAU} / \mathrm{mL}$ were excluded.

Results: The median age was 59 years and the male gender predominated $(n=81,70.4 \%)$. AFP and DCP response was identified in 91 (79.1\%) and 77 (66.9\%) patients after TACE. Although progression-free survival (PFS) did not differ according to AFP response $(P=0.150)$, AFP responders showed significantly better overall survival (OS) than non-responders (34.9 vs. 13.2 months; $P=0.002$ ). In contrast, DCP response did not influence either PFS or OS (all $P>0.05)$. Multivariate analyses showed that gamma-glutamyltranspeptidase and baseline AFP were predictors of PFS (all $P<0.05$ ) and that male gender, the presence of liver cirrhosis, baseline DCP, number of measurable tumors and AFP response were independent predictors of OS (all $P<0.05$ ).
\end{abstract}

Conclusions: AFP response and higher baseline DCP level are significant predictors of OS in treatment-naïve patients with HCC receiving TACE who showed pretreatment elevation of both AFP and DCP.

Keywords: Alpha-fetoprotein, Des gamma carboxy prothrombin, Transarterial chemoembolization, Tumor marker response, Hepatocellular carcinoma, Prognosis, Survival

\section{Background}

Hepatocellular carcinoma (HCC) is the third most common cause of cancer-related death globally [1]. Unless $\mathrm{HCC}$ is diagnosed at an early stage when liver transplantation, hepatic resection, and radiofrequency ablation are feasible, a poor prognosis is expected due to the

\footnotetext{
* Correspondence: DRPJY@yuhs.ac

${ }^{\dagger}$ Equal contributors

'Department of Internal Medicine, Yonsei University College of Medicine, 250

Seongsanno, Seodaemun-gu, Seoul 120-752, Korea

${ }^{3}$ Liver Cancer Special Clinic, Yonsei University College of Medicine, Seoul, Korea

Full list of author information is available at the end of the article
}

limited treatment options [2]. Although several treatment modalities have been applied to advanced HCC, [3,4] only trans-arterial chemoembolization (TACE) [5-10] and Sorafenib [11] exhibit survival benefit. Accordingly, TACE and Sorafenib are recommended for HCC in the intermediate and advanced Barcelona Clinic of Liver Cancer (BCLC) stages, respectively [12,13].

Alpha-fetoprotein (AFP) was first described about 40 years ago and is proposed as a screening and diagnostic tool for HCC [14-19]. Recently, the national comprehensive cancer network guidelines also proposed AFP as a alternative tool for diagnosing HCC [20]. Though there is no

\section{Ciomed Central}


definitive evidence to support an absolute value of AFP cut-offs [21,22]. Moreover, several studies have reported that changes in AFP levels may predict treatment outcome [23-25]. A recent study showed a correlation between AFP response and radiologic response, time-toprogression (TTP), progression-free survival (PFS), and overall survival (OS) in patients treated with loco-regional therapies [26,27]. In contrast, controversies regarding the diagnostic role of des gamma carboxy prothrombin (DCP) remain. However, the clinical significance of DCP is emphasized in Asia [28]. Recently, its clinical usefulness was emphasized in a different ethnic group [17,29,30].

The primary aim of this study was to determine the clinical utility of AFP and DCP as predictors of treatment outcome in patients with HCC undergoing TACE.

\section{Patients and methods Patients}

Between January 2003 and December 2005, a total of 270 patients underwent TACE as an initial treatment modality at Severance Hospital, Yonsei University College of Medicine, Seoul, Korea. Of these, we excluded 104 with an AFP level $<20 \mathrm{ng} / \mathrm{mL}$ [31] or DCP level $<20 \mathrm{mAU} / \mathrm{mL}$, 47 without baseline or follow-up tumor markers, and four with curative resection after TACE. Finally, a total of 115 patients were recruited for statistical analysis and followed-up until December, 2009. The study protocol was approved by the independent institutional review board of our institute.

\section{Diagnosis of HCC}

$\mathrm{HCC}$ was diagnosed based on the guidelines of American Association for the Study of Liver Diseases [32]. Briefly, patients were diagnosed with HCC if they had a tumor with a maximum diameter $>2 \mathrm{~cm}$, typical features of $\mathrm{HCC}$ on dynamic computed tomography (CT) (defined as hyperattenuation in the arterial phase and early washout in the portal phase), and an AFP $>200 \mathrm{ng} / \mathrm{ml}$ [32]. If the maximum diameter of tumor was $1-2 \mathrm{~cm}$, dynamic CT and magnetic resonance imaging (MRI) were performed. HCC was diagnosed if coincidental typical features of HCC were noted. If the tumor did not satisfy the above criteria, a biopsy was performed. When the tumor was $<1 \mathrm{~cm}$, ultrasonography was repeated after 3 months.

\section{Treatment and response-evaluation protocols}

After diagnosis of HCC was confirmed, angiography was performed to identify the major arterial supply to HCC. TACE was conducted using a solution of 20-50 mg doxorubicin hydrochloride in a 5-20 ml mixed solution of lipiodol and contrast agent. Subsequently, embolization was performed using gelatin sponge particles after TACE. After TACE, occlusion of target vessels and absence of additional tumor blood supply was confirmed.
Radiological response evaluation using CT or MRI and tumor marker response were evaluated 3-4 weeks after TACE. If viable tumor remained at CT or MRI, TACE was repeated. After 2-3 consecutive TACE sessions, at the time of best radiologic response, radiological and tumor marker responses were evaluated. If compact lipiodolization was noted and no viable $\mathrm{HCC}$ was identified, than radiologic evaluation and tumor marker measurement were done within 3 months to assess $\mathrm{HCC}$ recurrence. If progressive disease was identified, other treatment modalities were considered.

\section{Tumor marker response evaluation}

Baseline AFP and DCP levels were determined before TACE. Follow up tumor marker were checked every 3 4 weeks after TACE concurrent with CT or MRI. To analyze tumor marker response, we determined AFP and DCP levels when the best radiologic response was reached after 2-3 consecutive sessions of TACE. Tumor marker response evaluation was performed when complete remission is observed after consecutive session of TACE in most of subjects, but tumor marker response also analyzed within subject who did not get complete remission. In these patients, tumor marker checked just before last TACE concluded as progressive diseases by mRECIST criteria was used. AFP/DCP levels were measured using a microparticle enzyme immunoassay (AFP, Bayer, Leverkusen, Germany; DCP, Sanko Junyaku Co., Tokyo, Japan). AFP response was defined as a reduction in AFP level of more than $50 \%$ from baseline, according to a previous study [27]. Similarly, DCP response was defined as a reduction in DCP level of more than $50 \%$ from baseline.

\section{Radiologic response evaluation}

Radiologic tumor response was evaluated using the WHO and modified RECIST criteria by CT or MRI. For the WHO criteria, minimum cross product was compared to baseline cross product for calculating change in size. Complete response (CR) was defined as complete disappearance; partial response (PR) was defined as 50\% decrease; progressive disease (PD) was defined as a more than $25 \%$ increase in the cross product from maximum decrease. All other findings were defined as stable disease (SD). In the mRECIST criteria, length of the major axis of a viable tumor was compared to baseline for calculating change in size. CR was taken as the absence of any enhancing tissue, PR as a $30 \%$ decrease in enhancing tissue, and $\mathrm{SD}$ as a less than $20 \%$ decrease.

\section{Calculation of progression-free and overall survival}

The progression-free survival (PFS) time is defined as the time from the TACE start date to the first observation of tumor progression confirmed by mRECIST criteria or death due to any cause. To account for the fact that some 
patients dropped out for reasons other than tumor progression, PFS for these patients was censored at the time of last follow-up. The overall survival (OS) was calculated from the time of study entry to death. If the patient had no recorded date of death or was still alive at the time of the analysis, OS for these patients was censored at the date that the patient was last seen alive.

\section{Statistical analysis}

An independent $t$-test or Mann-Whitney $U$ test was used to compare continuous variables, and a chi-square or Fisher's exact test was used to compare categorical variables between two groups (AFP responder vs. AFP non-responder and DCP responder $v s$. DCP non-responder). AFP and DCP response together with conventional clinical variables at the time of entry to the study were used to identify independent factors that influence PFS and OS via the Cox proportional hazards model. Hazard ratio (HR) and the corresponding 95\% confidence intervals (CI) were also indicated. Age, sex, etiology, anti-viral therapy, HBV-DNA positivity, Child Pugh classification, liver cirrhosis, GGT, baseline AFP and DCP, AFP response, DCP responce, BCLC stage, number of tumor, size of tumor, WHO response and mRECIST response were included in univariate regression test on PFS and OS. Gender, Child-Pugh Classification, GGT, AFP, DCP, number and size of tumor, BCLC stage were included in multivariate regression test on PFS. Gender, Cirrhosis, GGT, AFP response, Baseline DCP, number and size of tumor were included on OS analysis. PFS and OS were calculated using the Kaplan-Meier method and compared using a log rank test. Statistical analyses were performed using SPSS ver. 11.0 software (SPSS Inc., Chicago, Ill).

\section{Results}

\section{Baseline characteristics}

Baseline characteristics of the 115 patients are described in Table 1 . The median age was 59 years and male gender predominated $(n=81,70.4 \%)$. Hepatitis B virus was the most common etiology of HCC $(n=80,69.6 \%)$. The median baseline AFP and DCP were $296.7 \mathrm{ng} / \mathrm{mL}$ and $231 \mathrm{mAU} / \mathrm{mL}$, respectively. Median follow up was 26 (range, 1.2-75.9) months.

\section{Tumor marker responses}

After TACE, 91 (79.1\%) patients showed AFP response and $24(20.9 \%)$ were non-responders (Table 1). Baseline characteristics were similar between AFP responders and non-responders, except for the significantly higher proportion of Child-Pugh class A in AFP responders than non-responders (97.8 vs. $79.2 \%$; $P=0.004)$. In contrast, 77 (66.9\%) patients showed a DCP response, and 38 (33.1\%) did not (Table 1). DCP non-responders showed a significantly higher proportion of solitary HCC (65.8 vs. $45.4 \% ; P=0.048$ ).

\section{Objective responses after TACE and correlation with tumor marker responses}

Table 2 shows objective responses after TACE using WHO and mRECIST criteria and their correlations with AFP and DCP responses. Neither AFP nor DCP responses showed a significant correlation with radiological response evaluated using the WHO criteria. In contrast, AFP, but not DCP, response was significantly correlated with radiological response evaluated using the mRECIST criteria $(P=0.045)$.

\section{Independent predictors for PFS and OS}

Univariate and multivariate analyses were used to identify independent predictors of PFS and OS (Table 3). Regarding PFS prediction, gamma glutamyltranspeptidase (GGT) (HR, 1.003; 95\% CI 1.001-1.004; $P=0.012$ ) and baseline AFP (HR 1.000; 95\% CI 1.000-1.001; $P=0.049$ ) were identified as independent predictors. Regarding OS prediction, male gender (HR, 2.119; 95\% CI, 1.040-4.320; $P=0.039$ ), the presence of cirrhosis (HR, 2.319; 95\% CI, 1.281-4.201; $P=0.005)$, baseline DCP level (HR, 1.000; 95\% CI, 1.000$1.001 ; P=0.028)$, number of tumors(HR, $1.443 ; 95 \% \mathrm{CI}$, 1.035-2.011; $P=0.030)$ and AFP response (HR, 0.276; 95\% CI; 0.147-0.518; $P<0.001)$ were independent predictors of OS. The Kaplan-Meier curves of PFS and OS according to AFP and DCP responses are indicated in Figures 1 and 2.

\section{DCP response within higher DCP levels}

DCP response did not show statistical significance for prediction of PFS or OS after TACE. However, when we analyzed a subgroup of patients with a baseline DCP level > $200 \mathrm{mAU} / \mathrm{ml}$ [31], a significant correlation between DCP response and OS emerged (median 26.7 months in DCP responders vs. 7.5 months in DCP non-responders; log rank test $P=0.002$ ). Thus, application of DCP response to prediction of treatment response and the corresponding optimal cutoff values of baseline DCP level to enhance the treatment-outcome predictability of DCP response should be further investigated.

\section{Combined serological endpoint}

Sub-analysis was done to find out whether combined serological endpoint (AFP and/or DCP responses) would improve it prognostication [33]. AFP and/or DCP responders were stratified into combined tumor marker responders (cTM responders, $n=99$ ) whereas subjects without AFP and DCP responses were stratified into cTM non-responders $(n=16)$. PFS was similar between cTM responders and non-responders (15.1 vs. 10.5 months; log rank test, $P=0.259$ ) whereas OS was significantly longer in 
Table 1 Baseline characteristics

\begin{tabular}{|c|c|c|c|c|c|c|c|}
\hline \multirow[t]{2}{*}{ Variables } & \multicolumn{3}{|c|}{ AFP } & \multirow{2}{*}{$\begin{array}{c}P \\
\text { value }\end{array}$} & \multicolumn{2}{|l|}{ DCP } & \multirow{2}{*}{$\begin{array}{c}P \\
\text { value }\end{array}$} \\
\hline & $\begin{array}{l}\text { All patients } \\
(\mathrm{n}=115)\end{array}$ & $\begin{array}{l}\text { AFP responder } \\
(\mathrm{n}=91,79.1 \%)\end{array}$ & $\begin{array}{c}\text { AFP non-responder } \\
(\mathrm{n}=24,20.9 \%)\end{array}$ & & $\begin{array}{l}\text { DCP responder } \\
(\mathrm{n}=77,66.9 \%)\end{array}$ & $\begin{array}{c}\text { DCP non-responder } \\
(\mathrm{n}=38,33.1 \%)\end{array}$ & \\
\hline Age, years & $59(37-78)$ & $59(37-78)$ & $59(39-75)$ & 0.783 & $59(37-78)$ & $59.9(40-77)$ & 0.661 \\
\hline Male & $81(70.4)$ & $63(69.2)$ & $18(75.0)$ & 0.802 & $53(68.8)$ & $28(73.7)$ & 0.668 \\
\hline \multicolumn{8}{|l|}{ Etiology } \\
\hline HBV/ HCV/ Others & $80(69.5) / 18(15.7) / 17(14.8)$ & $63(69.2) / 15(16.5) / 13(14.3)$ & $17(70.8) / 3(12.5) / 4(16.7)$ & 0.883 & $53(68.8) / 13(16.9) / 11(14.3)$ & $27(71.0) / 5(13.2) / 6(15.8)$ & 0.908 \\
\hline Child-Pugh, A vs. B & $108(93.9) / 7(6.1)$ & $89(97.8) / 2(2.2)$ & $19(79.2) / 5(20.8)$ & 0.004 & $74(96.1)$ / $3(3.9)$ & $34(89.5) / 4(10.5)$ & 0.217 \\
\hline Liver cirrhosis & $72(62.6) / 43(37.4)$ & $56(61.5) / 35(38.5)$ & $16(66.7) / 8(33.3)$ & 0.813 & 46 (59.7) / 31 (40.3) & $26(68.4) / 12(31.6)$ & 0.417 \\
\hline \multicolumn{8}{|l|}{ Biochemical Variables } \\
\hline Platelet, $10^{3} / \mathrm{uL}$ & $127(38-414)$ & $134(38-332)$ & $108(64-414)$ & 0.585 & $123(38-332)$ & $133.5(60-414)$ & 0.467 \\
\hline $\mathrm{ALT}, \mathrm{IU} / \mathrm{L}$ & $38(12-315)$ & $39(12-315)$ & $38(18-116)$ & 0.088 & $39(12-257)$ & $37(18-315)$ & 0.561 \\
\hline Bilirubin, mg/dL & $0.7(0.2-13.4)$ & $0.7(0.2-3.0)$ & $0.6(0.3-13.4)$ & 0.405 & $0.7(0.2-3.0)$ & $0.6(0.2-13.4)$ & 0.462 \\
\hline AFP, ng/mL & $296.7(24.23-83000)$ & $320.95(24.23-50000)$ & $142.96(26-83000)$ & 0.496 & $320.95(24.23-83000)$ & $280.08(25.22-50000)$ & 0.774 \\
\hline $\mathrm{DCP}, \mathrm{mAU} / \mathrm{mL}$ & $231(20-2000)$ & $231(20-2000)$ & $228.5(23-2000)$ & 0.304 & $276(20-2000)$ & $62.5(20-2000)$ & 0.464 \\
\hline \multicolumn{8}{|l|}{ Number of tumor ${ }^{a}$} \\
\hline $1 / 2 / 3 />4$ & $\begin{array}{c}60(52.2) / 18(15.7) / \\
9(7.8) / 28(24.3)\end{array}$ & $\begin{array}{c}13(54.2) / 5(20.8) / \\
2(8.3) / 4(16.7)\end{array}$ & $\begin{array}{c}47(51,6) / 13(14.3) / \\
7(7.7) / 24(26.4)\end{array}$ & 0.732 & $\begin{array}{c}35(45.4) / 13(16.9) / \\
6(7.8) / 23(29.9)\end{array}$ & $\begin{array}{c}25(65,8) / 5(13.2) / \\
3(8.0) / 5(13.2)\end{array}$ & 0.160 \\
\hline Size of tumor, mm ${ }^{b}$ & $47(10-160)$ & $47(10-160)$ & $45.5(10-151)$ & 0.531 & $49(10-160)$ & $36(10-160)$ & 0.473 \\
\hline \multicolumn{8}{|l|}{ BCLC stage } \\
\hline$A / B / C$ & $62(53.9) / 49(42.6) / 4(3.5)$ & $47(51.6) / 40(44.0) / 4(4.4)$ & $15(62.5) / 9(37.5) / 0(0.0)$ & 0.484 & $40(51.9) / 36(46.8) / 1(1.3)$ & $22(57.9) / 13(34.2) / 3(7.9)$ & 0.117 \\
\hline \multicolumn{8}{|l|}{ TNM stage of LCSGJ } \\
\hline \multirow[t]{2}{*}{ I/ II/ III/ IVa } & $21(18.3) / 40(34.8) /$ & $19(20.9) / 29(31.9) /$ & $2(8.3) / 11(45.8) /$ & 0.412 & $9(11.7) / 31(40.3) /$ & $12(31.6) / 9(23.7) /$ & 0.027 \\
\hline & $42(36.5) / 12(10.4)$ & 34 (37.4)/ 9 (9.9) & $8(33.3) / 3(1.5)$ & & $27(35.1) / 10(13.0)$ & $15(39.5) / 2(5.3)$ & \\
\hline
\end{tabular}

Variables are expressed as $n$ (\%) or median (range).

AFP, alpha-fetoprotein; DCP, des gamma carboxy prothrombin; HBV, hepatitis B-virus; HCV, hepatitis C-virus; ALT, alanine aminotransferase; BCLC, Barcelona Clinic Liver Cancer; TNM, Tumor-Node-Metastasis; LCSGJ,

Liver Cancer Study Group of Japan. 
Table 2 Objective responses after TACE and correlation with tumor marker responses

\begin{tabular}{|c|c|c|c|c|c|c|}
\hline \multirow{2}{*}{$\begin{array}{l}\text { Radiologic } \\
\text { response }\end{array}$} & \multicolumn{2}{|c|}{ AFP response } & \multirow[t]{2}{*}{$P$ value } & \multicolumn{2}{|c|}{ DCP response } & \multirow[t]{2}{*}{$P$ value } \\
\hline & $\begin{array}{l}\text { AFP responder } \\
(\mathrm{n}=91,79.1 \%)\end{array}$ & $\begin{array}{l}\text { AFP non-responder } \\
\quad(n=24,20.9 \%)\end{array}$ & & $\begin{array}{l}\text { DCP responder } \\
(n=77,66.9 \%)\end{array}$ & $\begin{array}{l}\text { DCP non-responder } \\
\quad(n=38,33.1 \%)\end{array}$ & \\
\hline \multicolumn{7}{|l|}{ WHO criteria } \\
\hline Complete response & $0(0)$ & $0(0)$ & & $0(0)$ & $0(0)$ & \\
\hline Partial response & $17(18.7)$ & $3(12.5)$ & \multirow[t]{3}{*}{0.196} & $11(14.3)$ & $9(23.7)$ & \multirow[t]{3}{*}{0.308} \\
\hline Stable disease & $71(78.0)$ & $18(75.0)$ & & $63(81.8)$ & $26(68.4)$ & \\
\hline Progressive disease & $3(3.3)$ & $3(12.5)$ & & $3(3.9)$ & $3(7.9)$ & \\
\hline \multicolumn{7}{|l|}{ mRECIST criteria } \\
\hline Complete response & $70(76.9)$ & $13(54.2)$ & \multirow{4}{*}{0.045} & $55(71.4)$ & $28(73.7)$ & \multirow{4}{*}{0.298} \\
\hline Partial response & $11(12.1)$ & $3(12.5)$ & & $12(15.6)$ & $2(5.3)$ & \\
\hline Stable disease & $3(3.3)$ & $3(12.5)$ & & $4(5.2)$ & $2(5.3)$ & \\
\hline Progressive disease & $7(7.7)$ & $5(20.8)$ & & $6(7.8)$ & $6(15.7)$ & \\
\hline
\end{tabular}

Variables are expressed as $n$ (\%).

AFP, alpha-fetoprotein; DCP, des gamma carboxy prothrombin; WHO, World health organization; mRECIST, modified Response Evaluation Criteria in Solid Tumor.

Table 3 Independent predictors for progression-free and overall survival

\begin{tabular}{|c|c|c|c|c|c|c|c|c|}
\hline \multirow[t]{3}{*}{ Variables } & \multicolumn{4}{|c|}{ Progression-free survival } & \multicolumn{4}{|c|}{ Overall survival } \\
\hline & \multirow{2}{*}{$\frac{\text { Univariate }}{P \text { value }}$} & \multicolumn{3}{|c|}{ Multivariate } & \multirow{2}{*}{$\begin{array}{c}\text { Univariate } \\
P \text { value }\end{array}$} & \multicolumn{3}{|c|}{ Multivariate } \\
\hline & & $P$ value & HR & $95 \% \mathrm{Cl}$ & & $P$ value & HR & $95 \% \mathrm{Cl}$ \\
\hline Age, years & 0.770 & & - & - & 0.578 & & - & - \\
\hline Male & 0.028 & 0.443 & - & - & 0.013 & 0.039 & 2.119 & $1.040-4.320$ \\
\hline \multicolumn{9}{|l|}{ Etiology } \\
\hline Viral vs. others & 0.252 & & - & - & 0.916 & & - & - \\
\hline Anti-viral therapy & 0.325 & & - & - & 0.047 & 0.453 & - & - \\
\hline HBV-DNA positivity & 0.165 & & - & - & 0.231 & & - & - \\
\hline HBeAg positivity & 0.234 & & - & - & 0.324 & & - & - \\
\hline Child-Pugh class, A vs. B & 0.040 & 0.832 & - & - & 0.787 & & - & - \\
\hline Liver cirrhosis & 0.101 & & - & - & 0.002 & 0.005 & 2.319 & $1.281-4.201$ \\
\hline GGT & 0.001 & 0.012 & 1.003 & $1.001-1.004$ & 0.014 & 0.068 & - & - \\
\hline \multicolumn{9}{|l|}{ Tumor marker } \\
\hline Baseline AFP & 0.008 & 0.049 & 1.000 & $1.000-1.001$ & 0.486 & & - & - \\
\hline Baseline DCP & 0.039 & 0.686 & - & - & 0.001 & 0.028 & 1.000 & $1.000-1.001$ \\
\hline AFP response & 0.155 & & - & - & 0.023 & $<0.001$ & 0.276 & $0.147-0.518$ \\
\hline DCP response & 0.756 & & - & - & 0.205 & & - & - \\
\hline $\mathrm{BCLC}$ stage, $\mathrm{A}$ vs. $\geq \mathrm{B}$ & 0.002 & 0.409 & - & - & 0.003 & 0.502 & - & - \\
\hline Number of tumor ${ }^{a}$ & 0.001 & 0.373 & - & - & $<0.001$ & 0.030 & 1.443 & $1.035-2.011$ \\
\hline Size of Tumor ${ }^{b}$ & 0.021 & 0.927 & - & - & $<0.001$ & 0.085 & - & - \\
\hline \multicolumn{9}{|l|}{ WHO response } \\
\hline$C R+P R+S D$ vs. $P D$ & 0.419 & & - & - & 0.945 & & - & - \\
\hline \multicolumn{9}{|l|}{ mRECIST } \\
\hline$C R+P R+S D$ vs. $P D$ & 0.107 & & - & - & 0.548 & & - & - \\
\hline
\end{tabular}

${ }^{a}$ number of measurable lesion, ${ }^{b}$ total size of measurable lesion.

$\mathrm{HR}$, hazard ratio; $\mathrm{Cl}$, confidence interval; AFP, alpha-fetoprotein; DCP, des gamma carboxy prothrombin; BCLC, Barcelona Clinic Liver Cancer.

Reference value: others, Child-Pugh class $B, B C L C$ stage $\geq B, P D$ with WHO criteria, and PD with mRECIST criteria. 


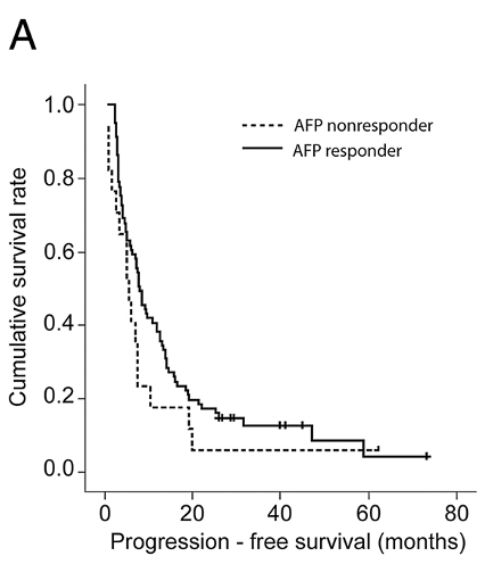

B

Figure 1 Progression-free (PFS) and overall survival (OS) curves of AFP responder and non-responder. PFS was similar between AFP
responders and non-responders (8.0 vs. 5.5 months; log rank test, $P=0.150 ;(\mathbf{A})$ ) whereas OS were significantly better in AFP responder than non-
responder. (34.9 vs. 13.2 months; log rank test, $P=0.020 ;(\mathbf{B})$ ).

cTM responders than non-responders (39.0 vs. 21.5 months; log rank test, $P=0.011)$. In addition, CTM response was selected as one of independent predictors of OS (HR 0.312; 95\% CI $0.150-0.649 ; P=0.002)$, together with tumor size and cirrhosis. However, cTM response did not predict PFS independently.

\section{Discordance between CTM response and radiologic response}

We divided the study population according to cTM and radiological responses. Definition of cTM response described at combined serological endpoint. Similarly, radiologic responders were defined as patients with $\mathrm{CR} /$ $\mathrm{PR} / \mathrm{SD}$ and radiologic non-responders as those with $\mathrm{PD}$ using the mRECIST criteria. Using these definitions, eight $(6.9 \%)$ cTM responders experienced a radiologic non-response and 12 (10.4\%) cTM non-responders experienced radiologic responses; these were categorized as discordant.

Baseline albumin level was identified as an independent predictor of discordance between cTM response and radiologic response (HR, 2.747; 95\% CI, 1.266-2.963; $P=0.011)$. Analysis of the discordant group $(n=20)$ revealed that the PFS and OS of eight CTM responders with radiologic non-response was not statistically different from that of 12 cTM non-responders with radiologic response (5.1 vs. 5.1 months; $P=0.828$ for PFS and 33.8 vs. 7.5 months; $P=0.354$ for OS) [Additional file 1].

\section{Discussion}

Tumor response evaluation using CT or MRI after systemic chemotherapy or loco-regional treatment is widely used to
A

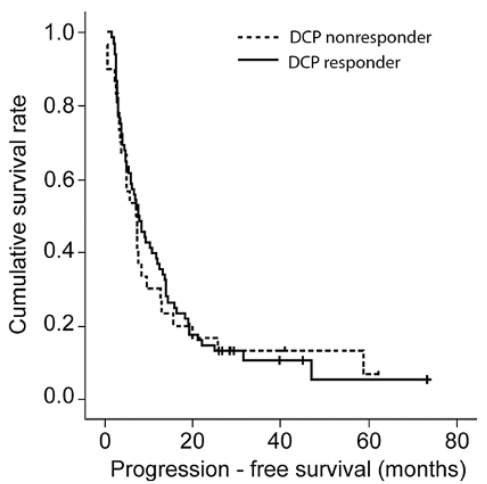

B

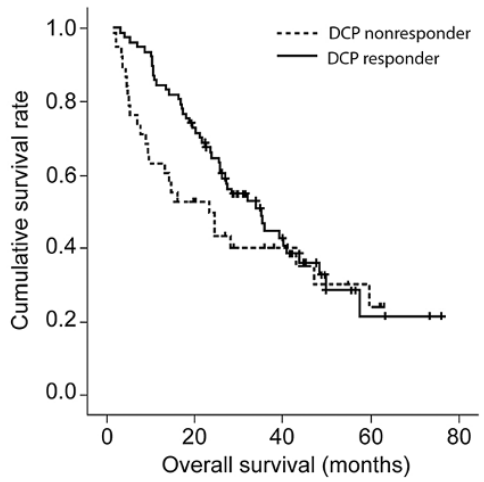

Figure 2 Progression-free survival (PFS) and overall survival (OS) curves of DCP responder and non-responder. Both PFS and OS were not significantly different between DCP responder and non-responder (7.8 vs.7.3 months; log rank test, $P=0.755$ for PFS (A) and 34.9 vs. 23.2 months; log rank test, $P=0.203$ for OS (B)). 
decide whether to treat further or change treatment strategies. However, high cost, radiation hazard, and associated cancer risks are drawbacks to these response evaluation modalities, [34] whereas tumor marker evaluation after anti-cancer treatment is rapid, easier to estimate, and less expensive. Thus, the clinical implications of tumor response evaluation using tumor markers have been continuously investigated [35-38].

This study also showed that AFP response can be an independent predictor of $\mathrm{OS}$ in patients undergoing TACE as the first treatment modality, whereas radiologic response was not significant in predicting PFS and OS. Several previous studies have also proposed the clinical usefulness of AFP response. Riaz et al. [27] proposed AFP response after loco-regional therapy as an ancillary method of assessing tumor response and survival, as well as an early objective screening tool for progression by imaging. Furthermore, the supplementary role of AFP response for tumor response evaluation and prediction of better survival and extrahepatic metastasis in patients undergoing hepatic arterial infusional chemotherapy, localized concurrent chemoradiation therapy, and antiangiogenic treatment such as Sorafenib and Bevacizumab has been proposed $[26,36,37]$. However, to our disappointment, AFP response didn't show its novel value of prediction in PFS of HCC patients. It might be caused by that all subjects did not have the same follow-up period and timing of assessment scan, furthermore definition of PFS might be subject to bias. So it could be a limitation of our study.

The baseline AFP level in our study also showed statistical significance for predicting PFS in a multivariate analysis $(P=0.035)$. Similarly, the significance of the prognostic role of baseline AFP level has been accepted in previous studies and several staging systems [39,40]. In contrast, baseline DCP level was significantly associated with OS in our study. Several other studies investigated the usefulness of baseline DCP level, and demonstrated that higher baseline DCP level was significantly correlated with poor prognosis in HBV-related HCC and with a higher risk of recurrence after curative treatment [35,41]. Although the reasons why HCC with a higher baseline DCP level is related to poor prognosis remain uncertain, it may in part be due to the fact that the higher baseline DCP level is significantly associated with the presence of vascular invasion, intra-hepatic metastasis, tumor size, Tumor-Node-Metastasis (TNM) stage, and a high frequency of tumor recurrence [42].

When we consider that only viable $\mathrm{HCC}$ can produce AFP and that the mRECIST criteria were developed to evaluate the amount of viable HCC, it is not surprising that AFP response showed a significant correlation to tumor response evaluated by mRECIST criteria. Although DCP is also produced by viable HCC, DCP response was not correlated with mRECIST response. This may be because, in contrast to AFP, DCP can be produced in surrounding non-cancer tissues after being stimulated by HCC [42], which might have attenuated the correlation between DCP response and radiologic tumor response by the mRECIST criteria. This also supports our result that DCP response was not significant for predicting PFS or OS after TACE. Because the WHO criteria do not consider specific situations (such as necrosis and the viable portion of $\mathrm{HCC}$ ) neither the AFP nor DCP responses were correlated with radiologic response evaluation by the WHO criteria.

We further analyzed patients showing discordant outcomes assessed by CTM response and radiologic response, because in this situation physicians must decide whether to maintain the current treatment modality or change it. Although baseline albumin level was identified as a predictor of discordance between CTM response and radiologic response, there was no statistical difference in OS between cTM responders with radiologic non-response and those with cTM non-response but radiologic response (33.8 vs. 7.5 months; $P=0.354$ ). Because a longer OS was noted in patients with cTM response and radiologic nonresponse in spite of the lack of statistical significance and because the clinical significance of the CTM response might have been attenuated due to the small discordant sub-population, a larger study is needed to reveal the role of cTM response in these cases. In the same context, if the role of CTM response in discordant cases can be demonstrated, CTM non-responders who experience radiologic response may need to have their disease progression monitored closely.

Interestingly, baseline GGT level was identified as an independent prognostic factor of PFS, similar to a recent study that proposed that GGT level is an important prognostic factor in patients with BCLC-intermediate HCC treated with TACE [43]. Considering that GGT level is associated with oxidative stress and resistance to platinum drugs $[44,45]$, the prognostic value of GGT levels for discriminating subgroups with different risks of disease progression or mortality should be determined.

This study has limitations. First, this was a retrospective study with a relatively small sample size. Also, some study subjects were included in article published recently and analyzed about prognostic value of AFP and DCP by the same institute [46]. However, the aim of this study is clearly different from previous one focusing on the prognostic value of baseline AFP and DCP in all patients with treatment-naïve HCC. In the present study, we focused on the prognostic value of the responses of AFP and DCP by TACE. Second, we excluded patients with low baseline AFP or DCP levels before TACE. Our results might not apply to patients with low baseline AFP or DCP levels. 
However, because we simply investigated the prognostic values of AFP and DCP response simultaneously, we inevitably selected only patients with elevated AFP and DCP in spite of a potential selection bias. Third, because AFP can be confounded by hepatic necroinflammation, the predictability of the AFP response might have been influenced. AFP response could be poor in patients with persistently elevated ALT after TACE. Furthermore, patients with persistently elevated ALT are reportedly associated with poor OS due to more rapid impairment of the liver function. Physicians should be cautious in applying baseline AFP or AFP response to patients suffering from active hepatitis or to those without elevated baseline AFP and DCP levels. Finally, considering that TACE was introduced as a palliative treatment for intermediate-stage HCC, many HCC patients with BCLC stage A in our study who were indicated for curative treatment underwent TACE. For several reasons, these patients decide to take TACE. Some of them refused surgical resection and others are unable to surgical resection because of their medical condition such as old age ( $>70 \mathrm{yrs}$ ) and poor general conditions (ECOG PS $\geq 2$ and/ or cachexia). Furthermore, sub-segmental TACE using iodized oil and a gelatin sponge remains an important therapeutic option for patients with HCC in Japan [47]. This is not surprising, because sub-segmental TACE as a curative treatment modality has become widely accepted in Korea as well as in Japan.

\section{Conclusions}

The present study demonstrated the clinical importance of AFP response and baseline DCP level for predicting OS in treatment-naïve patients with HCC undergoing TACE as an initial treatment modality. In the future, a treatment algorithm incorporating tumor marker response and radiologic response, which compensate for each other's drawbacks, should be established to more accurately predict treatment outcomes after TACE.

\section{Additional file}

Additional file 1: Table S1. Independent predictors between CTM responder with Radiologic non-responder $(n=8)$ and CTM nonresponder with radiologic responder $(n=12)$. Figure S1. Progressionfree survival (PFS) and overall survival (OS) curves of TM responder with radiologic non-responder and TM non-responder with radiologic nonresponder. Both PFS and OS were not significantly different between TM responder with radiologic non-responder and TM non-responder with radiologic non-responder (5.1 vs. 5.1 months; log rank test, $P=0.828$ for PFS (A) and 33.8 vs. 7.5 months; log rank test, $P=0.354$ for $O S$ (B)). Figure S2. Progression-free survival (PFS) and overall survival (OS) curves of CTM responder with radiologic responder and CTM non-responder with radiologic non-responder. PFS was similar between CTM responder with radiologic responder and CTM non-responder with radiologic nonresponder (19.0 vs. 6.2 months; log rank test, $P=0.065$ for PFS (A)) whereas OS were significantly better in CTM responder with radiologic responder than CTM non-responder with radiologic non-responder (39.2 vs. 12.8 months; log rank test, $P=0.031$ for OS (B)).

\section{Abbreviations}

HCC: Hepatocellular carcinoma; TACE: Trans-arterial chemoembolization; BCLC: Barcelona clinic liver cancer; AFP: Alpha-fetoprotein; TTP: Time to progression; PFS: Progression free survival; OS: Overall survival; DCP: Des gamma carboxy prothrombin; WHO: World Health Organization; RECIST: Response evaluation criteria in solid tumor; mRECIST: Modified response evaluation criteria in solid tumor; $\mathrm{CT}$ : Computed tomography; MRI: Magnetic resonance image; CR: Complete remission; PR: Partial remission; PD: Progressive disease; SD: Stable disease; HR: Hazard ratio; Cl: Confidence interval; GGT: Gamma glutamyltranspeptidase; HBV: Hepatitis B-virus; HCV: Hepatitis C-virus; ALT: Alanine aminotransferase;

HBeAg: Hepatitis B e antigen; HBV-DNA: Hepatitis B virus-deoxyribonucleic acid; TNM: Tumor-Node-Metastasis; CTM: Combined tumor marker; LCSGJ: Liver cancer study group of Japan; ECOG PS: Eastern Cooperative Oncology Group performance status.

\section{Competing interest}

The authors declare that they have no competing interests.

\section{Authors' contributions}

Guarantor of the article: Jun Yong Park, MD, Specific author contributions: YKL and SUK organized the protocol, collected and analyzed the data, and prepared the manuscript. DYK, SHA, KHH, and CYC recruited the patients and assisted article preparation. DYL carried out transarterial chemoembolization in HCC. JYP had the original idea for the study, was involved in the study design, and assisted article preparation. All authors read and approved the final manuscript.

\section{Acknowledgement}

This work was supported by the grant of the Bilateral International Collaborative R\&D Program from the Ministry of Knowledge Economy and by a grant of the Korea Healthcare technology R\&D Project, Ministry of Health and Welfare, Republic of Korea (A102065).

\section{Grant support}

This study was supported by a grant of the Korea Healthcare technology R \& D project, Ministry of Health and Welfare, Republic of Korea (A102065).

\section{Author details}

${ }^{1}$ Department of Internal Medicine, Yonsei University College of Medicine, 250 Seongsanno, Seodaemun-gu, Seoul 120-752, Korea. ${ }^{2}$ Department of Radiology, Yonsei University College of Medicine, Seoul, Korea. ${ }^{3}$ Liver Cancer Special Clinic, Yonsei University College of Medicine, Seoul, Korea. ${ }^{4}$ Liver Cirrhosis Clinical Research Center, Seoul, Korea. ${ }^{5}$ Brain Korea 21 Project for Medical Science, Seoul, Korea.

Received: 2 April 2012 Accepted: 26 November 2012 Published: 3 January 2013

\section{References}

1. Jemal $A$, Ward $E$, Hao $Y$, Thun M: Trends in the leading causes of death in the United States, 1970-2002. JAMA 2005, 294(10):1255-1259.

2. Han $\mathrm{KH}, \mathrm{Ahn} \mathrm{SH}$ : How to predict HCC development in patients with chronic B viral liver disease? Intervirology 2005, 48(1):23-28.

3. Han KH, Seong J, Kim JK, Ahn SH, Lee do Y, Chon CY: Pilot clinical trial of localized concurrent chemoradiation therapy for locally advanced hepatocellular carcinoma with portal vein thrombosis. Cancer 2008, 113(5):995-1003.

4. Ueshima K, Kudo M, Takita M, Nagai T, Tatsumi C, Ueda T, Kitai S, Ishikawa E, Yada N, Inoue T, et al: Hepatic arterial infusion chemotherapy using lowdose 5-fluorouracil and cisplatin for advanced hepatocellular carcinoma. Oncology 2010, 78(Suppl 1):148-153.

5. Llovet JM, Real MI, Montana X, Planas R, Coll S, Aponte J, Ayuso C, Sala M, Muchart J, Sola R, et al: Arterial embolisation or chemoembolisation versus symptomatic treatment in patients with unresectable hepatocellular carcinoma: a randomised controlled trial. Lancet 2002, 359(9319):1734-1739.

6. Maluccio M, Covey AM, Gandhi R, Gonen M, Getrajdman Gl, Brody LA, Fong $Y$, Jarnagin W, D'Angelica M, Blumgart $L$, et al: Comparison of survival rates after bland arterial embolization and ablation versus surgical resection 
for treating solitary hepatocellular carcinoma up to $7 \mathrm{~cm}$. J Vasc Interv Radiol 2005, 16(7):955-961.

7. Maluccio MA, Covey AM, Porat LB, Schubert J, Brody LA, Sofocleous CT, Getrajdman Gl, Jarnagin W, Dematteo R, Blumgart LH, et al: Transcatheter arterial embolization with only particles for the treatment of unresectable hepatocellular carcinoma. J Vasc Interv Radiol 2008, 19(6):862-869.

8. Ramsey DE, Kernagis LY, Soulen MC, Geschwind JF: Chemoembolization of hepatocellular carcinoma. J Vasc Interv Radiol 2002,

13(9 Pt 2):S211-221

9. Yamakado K, Nakatsuka A, Takaki H, Yokoi H, Usui M, Sakurai H, Isaji S, Shiraki K, Fuke H, Uemoto S, et al: Early-stage hepatocellular carcinoma: radiofrequency ablation combined with chemoembolization versus hepatectomy. Radiology 2008, 247(1):260-266.

10. Kim SU, Kim do Y, Park JY, Ahn SH, Nah HJ, Chon CY, Han KH: Hepatocellular carcinoma presenting with bone metastasis: clinical characteristics and prognostic factors. J Cancer Res Clin Oncol 2008, 134(12):1377-1384.

11. Llovet JM, Ricci S, Mazzaferro V, Hilgard P, Gane E, Blanc JF, de Oliveira AC, Santoro A, Raoul JL, Forner A, et al: Sorafenib in advanced hepatocellular carcinoma. N Engl J Med 2008, 359(4):378-390.

12. Llovet JM, Bruix J: Systematic review of randomized trials for unresectable hepatocellular carcinoma: Chemoembolization improves survival. Hepatology 2003, 37(2):429-442.

13. Lo CM, Ngan H, Tso WK, Liu CL, Lam CM, Poon RT, Fan ST, Wong J: Randomized controlled trial of transarterial lipiodol chemoembolization for unresectable hepatocellular carcinoma. Hepatology 2002, 35(5):1164-1171.

14. Chen DS, Sung JL: Serum alphafetoprotein in hepatocellular carcinoma. Cancer 1977, 40(2):779-783.

15. Eleftheriou N, Thomas H, Heathcote J, Sherlock S: Proceedings: Serum alphafetoprotein levels in liver disease: relation to hepatocellular regeneration and development of hepatoma. Gut 1975, 16(10):835

16. Izuno K, Fujiyama S, Yamasaki K, Sato M, Sato T: Early detection of hepatocellular carcinoma associated with cirrhosis by combined assay of des-gamma-carboxy prothrombin and alpha-fetoprotein: a prospective study. Hepatogastroenterology 1995, 42(4):387-393.

17. Pateron D, Ganne N, Trinchet JC, Aurousseau MH, Mal F, Meicler C, Coderc E, Reboullet P, Beaugrand M: Prospective study of screening for hepatocellular carcinoma in Caucasian patients with cirrhosis. $J$ Hepatol 1994, 20(1):65-71.

18. Trevisani F, D'Intino PE, Morselli-Labate AM, Mazzella G, Accogli E, Caraceni P, Domenicali M, De Notariis S, Roda E, Bernardi M: Serum alphafetoprotein for diagnosis of hepatocellular carcinoma in patients with chronic liver disease: influence of HBsAg and anti-HCV status. J Hepatol 2001, 34(4):570-575.

19. Zoli M, Magalotti D, Bianchi G, Gueli C, Marchesini G, Pisi E: Efficacy of a surveillance program for early detection of hepatocellular carcinoma. Cancer 1996, 78(5):977-985.

20. Benson AB 3rd, Abrams TA, Ben-Josef E, Bloomston PM, Botha JF, Clary BM, Covey A, Curley SA, D'Angelica MI, Davila R, et al: NCCN clinical practice guidelines in oncology: hepatobiliary cancers. J Natl Compr Canc Netw 2009, 7(4):350-391

21. Levy I, Greig PD, Gallinger S, Langer B, Sherman M: Resection of hepatocellular carcinoma without preoperative tumor biopsy. Ann Surg 2001, 234(2):206-209.

22. Torzilli G, Minagawa M, Takayama T, Inoue K, Hui AM, Kubota K, Ohtomo K, Makuuchi M: Accurate preoperative evaluation of liver mass lesions without fine-needle biopsy. Hepatology 1999, 30(4):889-893.

23. Chan SL, Mo FK, Johnson PJ, Hui EP, Ma BB, Ho WM, Lam KC, Chan AT, Mok TS, Yeo W: New utility of an old marker: serial alpha-fetoprotein measurement in predicting radiologic response and survival of patients with hepatocellular carcinoma undergoing systemic chemotherapy J Clin Oncol 2009, 27(3):446-452.

24. Vora SR, Zheng H, Stadler ZK, Fuchs CS, Zhu AX: Serum alpha-fetoprotein response as a surrogate for clinical outcome in patients receiving systemic therapy for advanced hepatocellular carcinoma. Oncologist 2009, 14(7):717-725

25. Chan SL, Chan AT, Yeo W: Role of alpha-fetoprotein in hepatocellular carcinoma: prognostication, treatment monitoring or both? Future Oncol 2009, 5(6):889-899
26. Kim BK, Ahn SH, Seong JS, Park JY, Kim do Y, Kim JK, Lee do Y, Lee KH, Han $\mathrm{KH}$ : Early alpha-fetoprotein response as a predictor for clinical outcome after localized concurrent chemoradiotherapy for advanced hepatocellular carcinoma. Liver Int 2011, 31(3):369-376.

27. Riaz A, Ryu RK, Kulik LM, Mulcahy MF, Lewandowski RJ, Minocha J, Ibrahim SM, Sato KT, Baker T, Miller FH, et al: Alpha-fetoprotein response after locoregional therapy for hepatocellular carcinoma: oncologic marker of radiologic response, progression, and survival. J Clin Oncol 2009, 27(34):5734-5742.

28. Fujiyama S, Tanaka M, Maeda S, Ashihara H, Hirata R, Tomita K: Tumor markers in early diagnosis, follow-up and management of patients with hepatocellular carcinoma. Oncology 2002, 62(Suppl 1):57-63.

29. Semela D, Dufour JF: Angiogenesis and hepatocellular carcinoma. J Hepatol 2004, 41(5):864-880.

30. Sharma B, Srinivasan R, Chawla YK, Kapil S, Saini N, Singla B, Chakraborthy A, Kalra N, Duseja A, Dhiman RK: Clinical utility of prothrombin induced by vitamin $\mathrm{K}$ absence in the detection of hepatocellular carcinoma in Indian population. Hepatol Int 2010, 4(3):569-576.

31. Marrero JA, Feng Z, Wang $Y$, Nguyen $M H$, Befeler AS, Roberts LR, Reddy KR, Harnois D, Llovet JM, Normolle D, et al: Alpha-fetoprotein, des-gamma carboxyprothrombin, and lectin-bound alpha-fetoprotein in early hepatocellular carcinoma. Gastroenterology 2009, 137(1):110-118.

32. Bruix J, Sherman M: Management of hepatocellular carcinoma. Hepatology 2005, 42(5):1208-1236.

33. Chon YE, Choi GH, Lee MH, Kim SU, Kim DY, Ahn SH, Kim KS, Choi JS, Han $\mathrm{KH}$, Chon CY, et al: Combined measurement of preoperative alphafetoprotein and des-gamma-carboxy prothrombin predicts recurrence after curative resection in patients with hepatitis-B-related hepatocellular carcinoma. Int J Cancer 2012, 131(10):2332-2341.

34. Brenner DJ, Hall EJ: Computed tomography-an increasing source of radiation exposure. N Engl J Med 2007, 357(22):2277-2284.

35. Kim HS, Park JW, Jang JS, Kim HJ, Shin WG, Kim KH, Lee JH, Kim HY, Jang MK: Prognostic values of alpha-fetoprotein and protein induced by vitamin $\mathrm{K}$ absence or antagonist-II in hepatitis $\mathrm{B}$ virus-related hepatocellular carcinoma: a prospective study. J Clin Gastroenterol 2009, 43(5):482-488

36. Lee MH, Kim SU, Kim DY, Ahn SH, Choi EH, Lee KH, Lee DY, Seong J, Han $\mathrm{KH}$, Chon $\mathrm{CY}$, et al: Early on-treatment predictions of clinical outcomes using AFP and DCP responses in patients with advanced hepatocellular carcinoma. J Gastroenterol Hepatol 2012, 27(2):313-322.

37. Shao YY, Lin ZZ, Hsu C, Shen YC, Hsu CH, Cheng AL: Early alphafetoprotein response predicts treatment efficacy of antiangiogenic systemic therapy in patients with advanced hepatocellular carcinoma. Cancer 2010, 116(19):4590-4596.

38. Liu X, Sheng W, Wang Y: An analysis of clinicopathological features and prognosis by comparing hepatoid adenocarcinoma of the stomach with AFP-producing gastric cancer. J Surg Oncol 2012, 106(3):299-303.

39. Manghisi O, Elba S, Mossa A, Giorgio A, Aloisio V, Perrotta A, Tardio B, Naja $C D$, Caturelli $E$, Calandra $M$, et al: A new prognostic system for hepatocellular carcinoma: a retrospective study of 435 patients: the Cancer of the Liver Italian Program (CLIP) investigators. Hepatology 1998, 28(3):751-755.

40. Nomura F, Ohnishi K, Tanabe $Y$ : Clinical features and prognosis of hepatocellular carcinoma with reference to serum alpha-fetoprotein levels. Analysis of 606 patients. Cancer 1989, 64(8):1700-1707.

41. Iwadou S, Nouso K, Kuwaki K, Kobayashi Y, Nakamura S, Tanaka H, Miyoshi K, Ohnishi H, Miyake $Y$, Shiraha $H$, et al: Time-dependent analysis of predisposing factors for the recurrence of hepatocellular carcinoma. Liver Int 2010, 30(7):1027-1032.

42. Tang W, Miki K, Kokudo N, Sugawara Y, Imamura H, Minagawa M, Yuan LW, Ohnishi S, Makuuchi M: Des-gamma-carboxy prothrombin in cancer and non-cancer liver tissue of patients with hepatocellular carcinoma. Int J Oncol 2003, 22(5):969-975.

43. Zhang JB, Chen Y, Zhang B, Xie X, Zhang L, Ge N, Ren Z, Ye SL: Prognostic significance of serum gamma-glutamyl transferase in patients with intermediate hepatocellular carcinoma treated with transcatheter arterial chemoembolization. Eur J Gastroenterol Hepatol 2011, 23(9):787-793.

44. Daubeuf S, Balin D, Leroy P, Visvikis A: Different mechanisms for gammaglutamyltransferase-dependent resistance to carboplatin and cisplatin. Biochem Pharmacol 2003, 66(4):595-604 
45. Lim JS, Yang JH, Chun BY, Kam S, Jacobs DR Jr, Lee DH: Is serum gammaglutamyltransferase inversely associated with serum antioxidants as a marker of oxidative stress? Free Radic Biol Med 2004, 37(7):1018-1023.

46. Kang SH, Kim do Y, Jeon SM, Ahn SH, Park JY, Kim SU, Kim JK, Lee KS, Chon $\mathrm{CY}$, Han KH: Clinical characteristics and prognosis of hepatocellular carcinoma with different sets of serum AFP and PIVKA-II levels. Eur J Gastroenterol Hepatol 2012, 24(7):849-856.

47. Takaki S, Sakaguchi H, Anai H, Tanaka T, Yamamoto K, Morimoto K, Nishiofuku H, Inoue M, Sueyoshi S, Nagata T, et al: Long-term outcome of transcatheter subsegmental and segmental arterial chemoemobolization using lipiodol for hepatocellular carcinoma. Cardiovasc Intervent Radiol 2012, 35(3):544-554.

doi:10.1186/1471-2407-13-5

Cite this article as: Lee et al:: Prognostic value of a-fetoprotein and des$\gamma$-carboxy prothrombin responses in patients with hepatocellular carcinoma treated with transarterial chemoembolization. BMC Cancer 2013 13:5.

\section{Submit your next manuscript to BioMed Central and take full advantage of:}

- Convenient online submission

- Thorough peer review

- No space constraints or color figure charges

- Immediate publication on acceptance

- Inclusion in PubMed, CAS, Scopus and Google Scholar

- Research which is freely available for redistribution 